\title{
THE ORIGIN OF TURQUOISE IN THE BURRO MOUNTAINS, NEW MEXICO. ${ }^{1}$
}

\author{
Sidney Paige.
}

INTRODUCTION.

During the summer of I9Io while engaged in geologic mapping of the Silver City quadrangle, New Mexico, an opportunity was afforded to examine the turquoise deposits of the Burro Mountains, New Mexico. These deposits, famous for the beauty of the gems produced, are located about Io miles southwest of Silver City, about $\mathrm{I}^{\mathrm{I} / 2}$ miles north of the mining camp of Tyrone. The mines are no longer productive, commercial turquoise having failed in depth.

Edward R. Zalinski has described these deposits in considerable detail in an article published in Economic Geology. ${ }^{2}$ The conclusions there reached regarding the genesis of the deposits hardly seem justified by the facts presented in this paper, nor with certain general geologic considerations. Also an examination of several microscopic thin sections by the writer, casts some doubt on certain mineral associations emphasized by Zalinski. In the following discussion, an endeavor will be made to reach a conclusion in accord with the facts that are known, supplemented by reasonable deductions from mineralogic relations.

\section{Geology.}

Rocks.-The turquoise is found in granitic and quartz monzonitic intrusive rocks. A pre-Cambrian complex comprising various granitic types was intruded in late or post Cretaceous time by a stock of quartz monzonite and quartz monzonite por-

${ }^{1}$ Published with the permission of the Director of the U. S. Geological Survey.

${ }^{2}$ Zalinski, Edw., "Turquoise in the Burro Mountains, New Mexico," Economic Geology, Vol. II., No. 5, pp. 464-492. 
phyry. Following this major intrusion, dikes of quartz monzonite porphyry broke through the parent mass and through the surrounding granitic rocks. The turquoise deposits are found both in the granite and in the later intrusive dike rock, a short distance north of the main quartz monzonite mass.

Fracturing and Mineralization.-Much of the region in question has been severely fractured and mineralized. To the south of the turquoise deposits and largely within the borders of the quartz monzonite area are important copper deposits which owe their value to processes of secondary enrichment operating upon lean pyritized fracture zones. ${ }^{1}$ The immediate country rock of the turquoise deposits is likewise severely fractured and the most important deposit occupies a fairly well defined fracture zone trending northeast and southwest.

Following or accompanying the fracturing of the granitic and quartz monzonitic rocks solutions, probably though not certainly, of magmatic origin circulated throughout the fractured zone and deposited in fissures and as replacement of the rocks, abundant cupriferous pyrite and quartz. Sericite was abundantly formed and ferromagnesian minerals, hornblende and biotite were either completely destroyed or altered to chloritic products.

Erosion and Oxidation.-There is evidence in a broad areal study of this region to show that the quartz monzonite intrusion took place in late Cretaceous or early Tertiary time. There is also evidence to show that a prolonged period of erosion followed the uplifts of Cretaceous rocks above the sea, and that in places the cover was stripped off the quartz monzonite masses exposing them to oxidizing influences. Of even greater importance in the case under consideration, there is evidence to prove that during Pleistocene time also the rocks in which the turquoise is found were subjected to subaerial erosion, during a period so prolonged, in fact, that planated rock cut surfaces were formed. ${ }^{2}$ The turquoise deposits occur from the surface to shallow depths and are thus obviously related to the surface of planation.

\footnotetext{
${ }^{1}$ Paige, Sidney, "Metalliferous Ore Deposits Near the Burro Mountains, Grant County, New Mexico," Bull. 470, U. S. Geol. Survey, pp. I32-I50.

"Paige, Sidney, "Rock-cut Surfaces in the Desert Ranges," Journal of Geology, to appear at an early date.
} 
The results of these conditions are the usual ones. Copper bearing sulphides have been altered to carbonates and silicates; limonite is formed in great abundance in veins where pyrite was once present, secondary chalcocite coats pyrite and forms commercial ore bodies, and large blocks of ground are completely leached of all copper-bearing minerals. In fact all the signs of extensive alteration in the zone of oxidation are present, in places extending to depths of 800 feet or more, as in the mines about one half mile to the south of the turquoise deposits.

To recapitulate the important geologic and physiographic considerations, quartz monzonitic intrusives have invaded a granitic pre-Cambrian complex. The intrusion was followed by severe fracturing and noteworthy mineralization. Two periods of prolonged erosion permitted thorough oxidation and hydration of the mineralized fracture zones. One of these periods was accomplished by physiographic conditions of such a nature that planated rock surfaces were formed. The turquoise deposits are closely related to a planated surface.

\section{The Occurrence, Mineralogic and Chemical Relations of THE TuRquoise.}

Occurrence.-Zalinski's descriptions furnish an excellent account of the occurrence of the turquoise.

"The turquoise was found in two forms, as vein turquoise filling cracks in the altered granite and as nuggets or concretions imbedded in kaolin. ${ }^{1}$

"The Elizabeth pocket extended from the second level to the surface a distance of 40 feet to 60 feet and the same quality of turquoise was found for I50 feet or more or along the vein. The distance between the walls is 40 feet.

"Some good turquoise was developed on the third level and sparingly on the fourth but here turquoise of the best quality was not plentiful and is associated with malachite and chrysocolla. ${ }^{2}$ It appears that an excess of copper gives the material a green color and also decreases the hardness. Whether depth is an important factor in the genesis or formation of ideal turquoise cannot be determined but at the present time all of the

${ }^{1}$ Much of the so-called kaolin in the rock sections examined by the writer proves to be sericite.

${ }^{2}$ Italics by the writer. 
fine turquoise is found at depths of Ioo feet or less. The vein turquoise fills cracks and fractures in the rock and is from one sixteenth up to three fourths of an inch in thickness. Most of it, however, is probably from one eighth to three eighths inches but it has been found up to one and a half inches thick. The nuggets or concretions are usually in the softer portions of the vein and along seams entirely imbedded in kaolin. They are various sizes and shapes, reniform, botryoidal, etc., and make the finest gems.

"Vein rock from near the Elizabeth pocket shows a medium fine to coarse-grained structure, traversed by a more than usual amount of quartz in veinlets and bands up to one half inch or more wide; these are sometimes open and contain cavities lined with quartz crystals. Vein turquoise sometimes contains small quartz crystals penetrating the turquoise from the sides of the vein. Bordering these quartz bands is kaolinized feldspar. The quartz often gives way to bright blue turquoise which partly or entirely fills the vein or occurs in isolated specks. Vein turquoise is often separated from the granite on one or both sides by quartz and also occurs in direct contact with the rock without quartz filling.

"The character of the turquoise varies from place to place along the vein and different kinds are also found closely associated."

Mineralogic Relations.-Two rock sections were examined microscopically by the writer. The relations immediately apparent are that a granular aggregate of quartz and sericite is cut by veinlets of quartz and turquoise. Closer inspection shows that the turquoise is later than most of the vein quartz. And it becomes apparent that the turquoise has been locally replaced partly by a brownish stained opaque substance and partly by a golden yellow mineral identified with a considerable degree of certainty as jarosite $\left(\mathrm{K}_{2} \mathrm{O}_{3} \mathrm{Fe}_{2} \mathrm{O}_{3} 4 \mathrm{SO}_{3} 6 \mathrm{H}_{2} \mathrm{O}\right)$.

Considering these minerals individually the following relations are made out. Quartz occurs in three generations. It is found first as a granular aggregate with sericite and represents in large part probably silica set free during sericitization, combined with the original quartz of the rock, which was quite abundant. Second it is found as well defined veinlets cutting the granular aggregate of quartz and sericite. Quartz of this same generation is likewise seen filling open fissures in the granular mass; and third, quartz is found cutting turquoise. 
Sericite likewise is found in three generations-first, with granular quartz, second, as replacement veins cutting the vein quartz and third, in veinlets cutting turquoise. Its relations in the second case have this peculiarity, that the sericite crystals penetrate quartz crystals, suggesting solutions of a considerable degree of chemical activity, and in the third case also a small crystal of quartz associated with sericite in a tiny veinlet is apparently penetrated by the sericite. In this case, however, there is the possibility that the quartz and sericite were deposited simultaneously and show relations which may be due to contemporaneity of formation.

The turquoise is later than most of the quartz and sericite (first and second generations). It is cut however by veinlets carrying jarosite, and kaolin (?) and by veinlets carrying either sericite or quartz or both.

The jarosite with quartz and kaolin (?) occupies the latest fractures in the rock which cut all the other constituents.

This bare statement of facts does not clearly set forth all the important relations. For example: The impression is gained from a study of the slides and likewise from an inspection of hand specimens, that two major stages of mineralization have taken place, one characterized by quartz and sericite, the other by turquoise and jarosite. This impression is based first on the intimate association of the sericite with the quartz, the one cutting the other indiscriminately, and second on the association of the turquoise with the jarosite and kaolin (?), many of the fractures in which these latter minerals are deposited strongly suggesting a distinct and single stage. Narrow turquoise veins run out into hair-like veinlets filled with jarosite and taken as a whole are a late phenomenon. Further, the turquoise has filled open fissures lined with crystalline quartz crystals.

The mineralization later than the turquoise consisted in the filling of veinlets with kaolin (?), jarosite, and quartz. This stage, the last, was from the quantitative side a very minor affair. The character of many of the smaller cracks suggest shrinkage 
due to sericitization, ${ }^{1}$ a process which may have been potent in opening these rocks to downward percolating waters.

Chemical Relations.-It is a recognized fact in chemical geology that a mineral may originate in several ways. The two sets of processes which concern the problem in hand are first, those of deposition from ascending solutions of magmatic origin, as opposed to (second) those processes connected with descending meteoric waters. The writer is strongly of the opinion that in no case can a proper conclusion be reached which fails to consider the geologic relations affecting the problem. What criteria point to a deep-seated origin of the turquoise and what do not? The chemical composition alone, $\mathrm{CuO}_{3} \mathrm{Al}_{2} \mathrm{O}_{3} 2 \mathrm{P}_{2} \mathrm{O}_{5} 9 \mathrm{H}_{2} \mathrm{O}$, is not diagnostic. Minerals of closely analogous composition (and they are many) are found in situations which point rather conclusively, in some cases, to a deep-seated origin, ${ }^{2}$ and in other cases to superficial origin. ${ }^{3}$ Nor can mineral association be relied on to furnish any facts diagnostic of deep-seated origin unless it be the occurrence of sericite cutting turquoise and associated with quartz which it has apparently penetrated or replaced. As pointed out before, however, such a relation of quartz and sericite may be due to simultaneous crystallization.

If now the constituents of the turquoise be examined individually from the standpoint of a possible source, two facts are suggestive. Copper is present to the amount of nearly 6.5 per cent. and phosphoric acid to the amount of nearly 30 per cent. The primary mineralization of the region is pyritic. The mines to the south in their lower levels contain pyrite, quartz, sericitized feldspar, and apatite, the latter in astonishingly clear unaltered, and in places, abundant crystals. In other words the waters which deposited pyrite and quartz and which were apparently competent to form sericite, did not attack apatite and brought in

${ }^{1}$ Lindgren, Waldemar, “Metasomatic Processes in Fissure Veins," Trans. A. I. M. E., Vol. XXX., I9or, p. 688.

${ }^{2}$ Apatite $(\mathrm{CaF}) \mathrm{Ca}_{4}\left(\mathrm{Po}_{4}\right)_{3}$, Amblygonite $\mathrm{Li}(\mathrm{AlF}) \mathrm{Po}_{4}$, Hinsdalite (2PbO$\left.{ }_{3} \mathrm{Al}_{2} \mathrm{O}_{3} 2 \mathrm{So}_{3} \mathrm{P}_{2} \mathrm{O}_{5} 6 \mathrm{H}_{2} \mathrm{O}\right)$, Alunite $\left(\mathrm{K}_{2} \mathrm{O}_{3} \mathrm{Al}_{2} \mathrm{O}_{3} 6 \mathrm{H}_{2} \mathrm{O}_{4} \mathrm{So}_{3} 6 \mathrm{H}_{2} \mathrm{O}\right)$.

${ }^{3}$ Chalcosiderite $\left(\mathrm{CuO}_{3} \mathrm{Fe}_{2} \mathrm{O}_{3} 2 \mathrm{P}_{2} \mathrm{O}_{5} 8 \mathrm{H}_{2} \mathrm{O}\right)$ - wavellite $\left(4 \mathrm{AlPo}_{4} 2 \mathrm{Al}(\mathrm{OH})_{3^{-}}\right.$ $9 \mathrm{H}_{2} \mathrm{O}$. 
a very low percentage (only a fraction of a per cent.) of copper.

Turning now to the oxidized zone we find invariably an enrichment of copper and in the turquoise deposits an absence of apatite. The inference is obvious, more strikingly so, when we consider that the turquoise likewise is confined strictly to the zone of oxidation.

An enquiry into the relations between the minerals found in the turquoise deposits and the probable chemical reactions taking place within the oxidized zone are found to be normal rather than otherwise. First as to sericite. Both Rosenbush and Vogt regard sericite as a common alteration product of the zone of weathering. Hickling ${ }^{1}$ in an article describing the China clay of Cornwall says: "Muscovite which represents the first stage of the transformation, is a perfectly normal decomposition product, formed whenever potash-feldspar is exposed to the influence of atmospheric moisture." The writer has observed sericite in numerous specimens of apparently fresh potassic igneous rocks, and I am informed by Professor T. Nelson Dale that in most of the New England granites which he has examined, white mica is present as an alteration product. It is apparent therefore that sericite is a stable mineral at the surface, provided conditions are not such as to favor kaolinization. Also, it has probably formed here in two ways, first through primary mineralization by carbonated water, ${ }^{2}$ and second by downward circulation of carbonated waters. The sericite found cutting the turquoise may be accounted for in this latter way. The fact that carbonated waters are competent to break down alkaline silicate is too firmly established to need further remark here, and it is the belief of the writer, that if sericite and quartz can result from the breaking down of potash feldspars in situ, the same solutions which performed the work are capable of depositing those minerals contemporaneously in veins in turquoise.

Taking up now the reactions which may have occurred to form turquoise. It is a reasonable assumption to imagine a fractured

${ }^{1}$ Hickling, George, "China-Clay: Its Nature and Origin," Transactions of the Institution of Mining Engineers, Vol. XXXVI., 1908-9, p. 24.

${ }^{2}$ When this level was buried by much rock now eroded away. 
zone within which the important minerals are sericite, quartz, some residual alkalic feldspar, apatite, and pyrite with which is associated a little chalcopyrite.

The oxidation of pyrite will result in the formation of sulphate solutions. Such solutions are capable of dissolving apatite, the alumina of the feldspar, and likewise attacking the sericite to some extent. Such solutions will contain both the sulphuric and phosphoric acid radicles; also copper, iron; potassium and lime. In such a solution, percolating downward, the phosphoric acid radicle on neutralization of the solution would be the first to combine with alumina. This reaction is the normal one in weakly acidulated waters at ordinary temperature. That copper likewise would be precipitated is normal. Just why it should enter into combination in the proper proportions necessary to form turquoise is a point that cannot be answered here, especially as there is evidence that gem turquoise is not always of an exactly identical chemical composition. The balance of all the factors necessary for the reaction were evidently present. The remaining bases may be considered to have passed on in solution.

It is considered probable that this process continued until much of the pyrite and all of the phosphoric acid and unaltered feldspar was depleted. A chemico-mineralogic argument in favor of such a process is found in the jarosite, which followed the turquoise in point of time and which is a hydrous sulphate of potassium and iron. The potassium may well have been derived from sericite and the iron from the pyrite.

Bischof says ${ }^{1}$ concerning the analysis of wavellite

$$
\left(4 \mathrm{AlPo}_{4} 2 \mathrm{AL}(\mathrm{OH})_{3} \& 9 \mathrm{H}_{2} \mathrm{O}\right. \text {-Dana ) : }
$$

"The analysis of wavellite by the method of Berzelius and Fuchs shows that phosphate of alumina cannot exist in solution with an alkaline silicate."

This statement is of interest when we consider that alkaline silicates were certainly present in the primary solutions which mineralized this territory. He says also: ${ }^{2}$

1 "Elements of Chemical and Physical Geology," Gustav Bishof, Vol. II., p. 33, Eng. edition.

${ }^{2}$ Op. cit., p. 33. 
"It still remains to be ascertained from what phosphatic mineral the phosphates of alumina in the waters of springs originates. The presence of phosphate of soda in water has already been pointed out and as the soluble salts of alumina are decomposed by phosphate of soda it is possible that it may originate from sulphate of alumina, which is frequently formed in beds of clay by the oxidation of iron pyrite."1

Of vivianite $\left(\mathrm{Fe}_{3} \mathrm{P}_{2} \mathrm{O}_{8}-8 \mathrm{H}_{2} \mathrm{O}-\right.$ Dana $)$ he says:

"Its association with iron pyrite on the one hand and with fossils on the other probably justifies the influence that the iron pyrite was converted, by oxidation, into sulphate and that the phosphate of iron was formed by the reaction of this salt with the phosphate of lime in the fossils."

Also :

"The phosphate of copper in the Virneberg at Rhembreitenbach, seems to have originated from oxidized copper pyrites. It is found chiefly in the outcrop of the lodes, in the clay slate rock and in the neighborhood of open clefts associated with tile ore, chalcedony and quartz. The tile ore, a mixture of earthy oxide of copper and iron ochre has undoubtedly originated from the alteration of copper pyrites; for it is sometimes pseudomorphous after this mineral and occurs in the same position. The occurrence of phosphate of copper at the outcrop of the lode and in the neighborhood of fissures, clearly shows that the water containing phosphate, probably phosphate of lime, came from the surface whether it derived the phosphate from the rock or from organic remains in it."

The bearing of these quotations is obvious: they tend to support reactions such as are postulated above to account for the turquoise.

\section{Conclusions.}

Summarizing the facts and deductions which have been presented above, we find that in favor of the hypothesis of deepseated origin, the following may be arrayed:

I. There is nothing in the inherent chemical composition of the turquoise to exclude such an origin. (Negative argument.)

2. The turquoise is cut by veinlets of sericite and quartz, inter-

${ }^{1}$ P. 34 .

${ }^{2}$ Pp. $34-35$.

${ }^{3}$ P. 35, Vol. II. 
grown in such a manner that heated waters are suggested. (This fact may be interpreted also as contemporaneous growth of sericite and quartz formed in the zone of weathering.)

In favor of an origin in the zone of weathering and at the same time opposed to the deep-seated origin are the following facts:

I. The deposits are found in the zone of weathering, are strictly confined to the uppermost portion of the zone of weathering, and are associated with copper minerals characteristic of the zone of weathering (malachite and chrysocolla).

2. Physiographic evidence proves the existence of long periods of erosion under such conditions, that if we assume the deposits as deep-seated we are confronted with two difficulties, the one to account for the invariable and significant position of all the turquoise of this region with respect to a planated surface, the other to show why the deposits have not either been removed by erosion or altered by the long processes of weathering to which they must have been subjected. To assume that the planated surface has accidentally arrived at the depth where original deepseated deposition took place would hardly be an argument.

3. There is nothing inherent in the chemical composition of the mineral to exclude it from an origin in the zone of weathering. In fact there are many hydrous phosphates of a more or less analogous composition which have undoubtedly originated in this way. (Negative argument.)

4. A search for the source of the material found in the turquoise indicates that the solutions producing primary mineralization in this region were probably inadequate. Apatite was not attacked and copper was introduced in very sparing quantity. On the other hand, in the zone of weathering apatite has been removed and a concentration of copper is the normal process.

5. Seeking the possible solutions from which the turquoise might have formed, we have some chemical data to show that phosphates of alumina probably did not exist in the solutions which caused the primary mineralization of this region. On the other hand we have in the zone of weathering a potent solvent for all the constituents found in the turquoise,- - sulphate solutions 
formed by the oxidation of pyrite known to have been present. Likewise the constituents of the turquoise were present at the time oxidation began to be effective.

6. Chemical laboratory experiments in the cold agree with the assumption that if the sulphuric and phosphoric acid radicle are present in a weak acid solution which gradually becomes neutralized, the phosphoric acid first will combine with alumina. Mineralogic evidence observed in rock sections indicates that such processes have taken place and that the depletion of phosphoric acid and alumina by leaching resulted finally in the precipitation of sulphates of potassium and iron probably derived from sericite and pyrite. 